\section{TEKANAN DARAH DAN HUBUNGANNYA DENGAN INDEKS MASSA TUBUH DAN AKTIFITAS FISIK PADA WANITA DEWASA}

\section{Blood Pressure and Its Relation to Body Mass Index and Physical Activity in Adult Women}

\author{
Eva Malinti, Evelin Malinti \\ Fakultas Ilmu Keperawatan Universitas Advent Indonesia
}

\section{Riwayat artikel}

Diajukan: 11 Maret 2020

Diterima: 27 Juli 2020

\section{Penulis Korespondensi:}

- Eva Malinti

- Fakultas Ilmu

Keperawatan

Universitas Advent

Indonesia

- eva.malinti@gmail.com

\section{Kata Kunci:}

Aktifitas Fisik, Indeks Massa Tubuh, Tekanan Darah, Wanita Dewasa

\begin{abstract}
Abstrak
Pendahuluan : Wanita dewasa yang tidak aktif secara fisik sering bermasalah dengan kondisi obesitas. Obesitas menjadi salah satu penyebab meningkatnya tekanan darah. Tujuan: Penelitian ini bertujuan untuk mengetahui apakah ada hubungan antara Indeks Massa Tubuh (IMT) yang menjadi indikator obesitas dan tingkat aktifitas fisik dengan tekanan darah wanita dewasa. Metode: Metode yang digunakan dalam penelitian ini adalah deskriptif analisis dengan pendekatan potong lintang. Instrumen yang digunakan dalam penelitian ini adalah stadiometer, timbangan badan digital dan spigmomanometer digital serta kuesioner aktifitas fisik. Responden dalam penelitian ini berusia 20-49 tahun yang belum pernah didiagnosa hipertensi. Hasil: Rata-rata IMT responden termasuk dalam kategori obesitas. Rata-rata tingkat aktifitas tergolong normal. Rata-rata tekanan darah sistolik tergolong meningkat sedangkan tekanan darah diastolik tergolong hipertensi tahap I. Hasil uji bivariat menunjukkan bahwa terdapat hubungan signifikan dengan arah korelasi positif antara IMT dengan tekanan darah sistolik maupun diastolik $(\mathrm{p}<.05)$. Namun antara aktifitas fisik dengan tekanan darah sistolik maupun diastolik tidak terdapat hubungan signifikan ( $\mathrm{p}>.05$ ).

Kesimpulan: Penelitian ini menunjukkan bahwa semakin tinggi IMT maka semakin tinggi tekanan darah, sehingga adalah penting bagi wanita dewasa untuk menurunkan berat badan untuk mengontrol tekanan darah. Perlu dilakukan penelitian terhadap faktor lain yang berhubungan dengan tekanan darah pada wanita dewasa.
\end{abstract}

Abstract
Background: Adult women who physically inactive often have problems with the condition of obesity which is one of the causes of increased blood pressure. Objective: This study aims to determine whether there is a relationship between Body Mass Index (BMI) as an indicator of obesity and the level of physical activity with blood pressure of adult women. MethodThe method used in this research is descriptive analysis with a cross-sectional approach. The instruments used in this study were stadiometers, digital body scales and digital spigmomanometers and physical activity questionnaires. Results: Respondents in this study were aged 20-49 years old who had never been diagnosed with hypertension. The average BMI of the respondents is categorized as obesity. The average level of activity is quite normal. The Average of systolic blood pressure was classified as elevated whereas diastolic blood pressure was classified as stage I hypertension. A bivariate test results showed that there was a significant correlation with positive direction between BMI and systolic and diastolic blood pressure ( $p<.05)$. However the physical activity with systolic and diastolic blood pressure was found no significant relationship ( $p>.05)$. Conclusion: The study implies that the higher the BMI the higher the blood pressure, so it is important for adult women to lose weight to control blood pressure. Further study needs to be done on other factors related to blood pressure in adult women. 


\section{PENDAHULUAN}

Lemak tubuh telah menjadi isu kesehatan dan isu sosial yang penting di zaman milenial ini. Pandangan setiap orang tentang lemak tubuh berbeda-beda. Gadis muda mengharapkan dan berusaha untuk menjaga atau memperoleh berat badan ideal (Nuttall, 2015). Namun bagi perempuan yang telah memasuki usia dewasa, berkeluarga, apalagi telah memiliki anak mempertahankan berat badan ideal dan menghilangkan lemak tubuh menjadi hal yang sulit, sehingga seolah-olah diabaikan. Hal ini menyebabkan semakin meningkatnya jumlah wanita dewasa dengan berat badan lebih dan obesitas. Salah satu faktor penyebab peningkatan berat badan adalah kurangnya aktifitas fisik (Abdul et al., 2018).

Prevalensi kelebihan berat badan (overweight) dan obesitas bedasarkan indeks massa tubuh di Indonesia semakin meningkat dari tahun ketahun. Pada tahun 2018, terjadi peningkatan sebanyak 2,1 persen pada jumlah penduduk dengan status berat badan lebih dan 7 persen peningkatan jumlah penduduk dengan obesitas dibanding tahun 2013. Seiring dengan meningkatnya jumlah penderita obesitas, penderita tekanan darah tinggi juga meningkat (Riskesdas, 2018). Kelebihan lemak tubuh merupakan faktor yang meningkatkan resiko berbagai penyakit kronis. Hal ini menyebabkan menurunnya kualitas hidup yang dirasakan dimasa tua pada kasus kelebihan berat badan atau obesitas (Stenholm et al., 2017).

Kurang aktifitas fisik beresiko obesitas dan keduanya merupakan resiko penyakit kardivaskular seperti hipertensi. Sebaliknya, aktifitas fisik yang rutin dilakukan dapat menurunkan berat badan serta menurunkan tekanan darah (Egan, 2017; Kim et al., 2017). Semakin meningkatnya prevalensi obesitas sejalan dengan meningkatnya kejadian hipertensi. Obesitas terjadi oleh karena ketidakseimbangan antara asupan energi dan energi yang dibakar. Gaya hidup sendentari, kurang aktifitas fisik, kebiasaan makan yang berlebihan serta faktor predisposisi lain seperti masalah psikologis dan faktor keturunan memiliki kontribusi dalam proses meningkatnya berat badan (Jiang et al., 2016).

Kondisi obesitas melalui mekanisme neuroendokrin berperan dalam peningkatan tekanan darah. Terjadi aktivasi sistem reninangitensin-aldosteron dan saraf simpatis mengakibatkan peningkatan tekanan darah dengan bertambahnya volume darah dan vasokonstriksi pembuluh darah. Selain itu terjadi masalah metabolik termasuk insulin resisten, dislipidemia, inflamasi yang mengganggu fungsi ginjal dan mempengaruhi tekanan darah (Hall et al., 2015).

Wanita dewasa muda dengan berat badan normal dan berat badan berlebih memiliki perbedaan signifikan pada tekanan darah baik sistolik dan diastolik. Wanita dengan berat badan berlebih memiliki tekanan darah yang lebih tinggi dibanding wanita dengan berat badan normal (Malinti and Lola, 2018). Penelitian lain yang dilakukan pada pria dewasa muda menunjukkan adanya korelasi antara indeks masa tubuh dengan tekanan darah (Malinti and Elon, 2019).

Aktif secara fisik merupakan faktor penting untuk dilakukan sebagai usaha modifikasi gaya hidup untuk meningkatkan status kesehatan termasuk menurunkan obesitas (West et al., 2018). Aktifitas fisik dapat mencegah tekanan darah tinggi dan jika dilakukan oleh penderita hipertensi dapat membatu menurunkan tekanan darah (Pescatello et al., 2019).

Penelitian ini dilakukan dengan maksud untuk mengkaji hubungan antara indeks massa tubuh sebagai salah satu indikator kegemukan dan tingkat aktifitas fisik dengan tekanan darah pada wanita dewasa.

\section{METODE}

Metode yang digunakan dalam penelitian ini adalah metode analisis dekriptif dengan design potong lintang. Variabel penelitian yang dihubungkan yaitu indeks masa tubuh, tingkat aktifitas fisik dan tekanan darah baik sistolik dan diastolik. Penelitian ini dilakukan di RW 13, Desa Cihanjuang Rahayu dengan jumlah responden sebanyak 55 orang wanita dewasa, berusia 20-49 tahun yang merupakan penduduk setempat. Teknik sampling yang digunakan adalah Purposive Sampling dengan kriteria inklusi: tidak pernah didiagnosa menderita hipertensi sebelumnya atau meminum obat antihipertensi.

Pengumpulan data dilakukan dengan mendatangi calon responden di rumah masingmasing. Responden yang bersedia berpartisipasi menandatangani surat persetujuan penelitian setelah diberikan penjelasan tentang tujuan penelitian. Setiap responden mendapatkan cindera mata sebagai ucapan terimakasih untuk partisipasi yang diberikan.

Pengukuran tekanan darah dilakukan pada lengan responden menggunakan OMRON spigmonanometer digital. Data aktifitas fisik diperoleh melalui pengisian kuesioner yang 
mengkategorikan aktifitas ringan sedang dan berat. Indeks masa tubuh diperoleh dengan cara mengukur tinggi dan menimbang berat badan respondendan selanjutnya dihitung menggunakan rumus Indeks Massa Tubuh (IMT).

Hasil pengukuran tekanan darah dikaterorikan berdasarkan klasifikasi menurut American Heart Association (AHA) 2017. Tekanan darah normal $(<120 /<80 \mathrm{mmHg})$, elevated/meningkat $\quad(120-129 /<80 \quad \mathrm{mmHg})$, hipertensi tahap 1 (130-139/80-89 $\mathrm{mmHg})$, hiperpertensi tahap $2(\geq 140 / \geq 90 \mathrm{mmHg})$. Indeks massa tubuh dikategorikan berdasarkan kategori IMT oleh World Health Organization (WHO) untuk penduduk Asia yaitu underweight $(<18,4)$, normal $(18,5-22,9)$, overweight $(23-24,9)$ dan obesitas $(\geq 25)$.

Analisa data dilakukan dengan mengolah data secara deskriptif yaitu presentase data demografi dan mencari rata-rata dari tekanan darah sistolik dan diastolik, IMT, dan aktifitas fisik. Selanjutnya dilakukan uji bivariat untuk hubungan antar variabel dengan uji spearman

\section{HASIL DAN PEMBAHASAN HASIL PENELITIAN}

Distribusi responden berdasarkan IMT, dan Aktifitas Fisik serta tekanan darah dapat dilihat dalam tabel 1. Golongan IMT secara berurutan yaitu, obesitas 63\%, normal $12 \%$ dan overweight $7 \%$. Lebih dari setengah responden memiliki tingkat aktifitas yang cukup baik yaitu $63 \%$ aktifitas normal, $15 \%$ aktifitas tinggi, namun $22 \%$ aktifitas rendah. Berdasarkan tekanan darah sistolik sebanyak $33 \%$ responden memiliki tekanan darah sistolik normal, $31 \%$ tekanan darah meningkat, $7 \%$ hipertensi tahap $1,27 \%$ hipertensi tahap 2, dan 2\% hipertensi urgency. Sebanyak $11 \%$ responden memiliki tekanan darah diastolik normal, $42 \%$ hipertensi tahap 1, 45\% hipertensi tahap 2, dan $2 \%$ hipertensi urgency.

Tabel 1. Distribusi Responden

\begin{tabular}{lll}
\hline Data & $\mathrm{N}$ & $\%$ \\
\hline IMT: & & \\
Normal & 12 & $24 \%$ \\
Overweight & 7 & $13 \%$ \\
Obesitas & 35 & $63 \%$ \\
Tingkat Aktifitas Fisik: & & \\
Rendah & 12 & $22 \%$ \\
Normal & 35 & $63 \%$ \\
Tinggi & 8 & $15 \%$ \\
Tekanan darah & & \\
Sistolik: & & \\
Normal & 18 & $33 \%$
\end{tabular}

\begin{tabular}{|c|c|c|}
\hline Meningkat & 17 & $31 \%$ \\
\hline Hipertensi I & 4 & $7 \%$ \\
\hline Hipertensi II & 15 & $27 \%$ \\
\hline Hipertensi Urgensy & 1 & $2 \%$ \\
\hline $\begin{array}{l}\text { Tekanan } \\
\text { Diastolik: }\end{array}$ & & \\
\hline Normal & 6 & $11 \%$ \\
\hline Meningkat & 0 & $0 \%$ \\
\hline Hipertensi I & 23 & $42 \%$ \\
\hline Hipertensi II & 25 & $45 \%$ \\
\hline Hipertensi Urgency & 1 & $2 \%$ \\
\hline
\end{tabular}

Responden ( $\mathrm{N}=55)$ memiliki rata-rata IMT 27,30 ( $\mathrm{SD}=5,20)$, dengan minimal IMT 18 dan maksimal IMT 41,4. Rata-rata aktifitas fisik adalah 34,16 poin $(\mathrm{SD}=5,34)$, dengan poin minimal 25 dan maksimal 49. Rata-rata tekanan darah sistolik adalah $127,03 \mathrm{mmHg}(\mathrm{SD}=17,84)$, minimal sistolik adalah $90 \mathrm{mmHg}$ dan maksimal $182 \mathrm{mmHg}$. Sedangkan rata-rata tekanan darah diastolik adalah $87,70 \mathrm{mmHg} \quad(\mathrm{SD}=11,14)$ dengan minimal diastolik $60 \mathrm{mmHg}$ dan maksimal diastolik $132 \mathrm{mmHg}$. Tabel 2 menunjukkan uji univariat Indeks masa tubuh, aktifitas fisik, dan tekanan darah.

Tabel 2. Rata-rata IMT, Aktifitas fisik, tekanan darah

\begin{tabular}{lccccc}
\hline Data & N & Min & Max & Mean & SD \\
\hline $\begin{array}{l}\text { IMT } \\
\text { Aktifitas }\end{array}$ & 55 & 18 & 41,4 & 27,30 & 5,20 \\
$\begin{array}{l}\text { Fisik } \\
\text { Tekanan }\end{array}$ & 55 & 25 & 49 & 34,16 & 5,34 \\
darah: & & & & & \\
Sistolik & 55 & 90 & 182 & 127,03 & 17,84 \\
Diastolik & 55 & 60 & 132 & 87,70 & 11,14 \\
\hline
\end{tabular}

Tabel 3 menunjukkan hasil uji bivariat antara IMT dengan tekanan darah dan aktifitas fisik dengan tekanan darah. Nilai $\mathrm{p}$ untuk IMT dan tekanan darah sistolik $=.018(\mathrm{r}=.319)$, sedang nilai $\mathrm{p}$ untuk IMT dan tekanan darah diastolik $=.012(\mathrm{r}=.338)$. Dilain pihak, aktifitas fisik dengan tekanan darah sistolik memiliki nilai $\mathrm{p}=.740 \quad(\mathrm{r}=.046)$, dan dengan diastolik $\mathrm{p}=.651$ $(\mathrm{r}=-062)$.

Tabel 3. Korelasi IMT, Aktifitas Fisik dan Tekanan darah

\begin{tabular}{llll}
\hline & Mean & $\mathrm{p}$ & $\mathrm{R}$ \\
\hline IMT & 27,30 & .018 & .391 \\
Sistolik & 127,03 & & \\
IMT & 27,30 & .012 & .338 \\
Diastolik & 87,70 & & \\
Aktifitas Fisik & 34,16 & .740 & .046 \\
Sistolik & 127,03 & &
\end{tabular}




\begin{tabular}{llll} 
Aktifitas Fisik & 34,16 & .651 & .062 \\
Diastolik & 87,70 & & \\
\hline
\end{tabular}

\section{PEMBAHASAN}

Hasil penelitian ini menunjukkan bahwa berdasarkan klasifikasi IMT untuk orang Asia (Lim et al., 2017), responden memiliki rentang IMT mulai dari normal sampai obesitas dengan rata-rata IMT $(27,30)$ tergolong obesitas. Ratarata poin aktifitas fisik responden tergolong dalam aktifitas normal. Tekanan darah responden mulai memiliki rentang dari normal sampai diatas hipertensi tahap II. Berdasarkan American Heart Association 2017 rata-rata tekanan darah sistolik responden tergolong mengalami peningkatan sedangkan tekanan darah diastolik tergolong hipertensi tahap I (Whelton et al., 2018).

Obesitas pada wanita semakin meningkat diseluruh dunia. Hal ini disebabkan oleh tingginya konsumsi karbohidrat, gula, lemak dan kurangnya aktifitas fisik. Wanita yang kelebihan berat badan beresiko tinggi nantinya mengalami obesitas yang selanjutnya menjadi penyebab berbagai penyakit tidak menular. Akumulasi lemak yang tinggi dalam tubuh meningkatkan penyakit kardiovaskular yang merupakan penyebab kematian wanita diusia muda (Youngwanichsetha, 2018). Kurang aktif secara fisik mendukung kondisi ini, sebaliknya menjadi aktif secara fisik menurunkan resiko mengalami gangguan jantung dan pembuluh darah (WHO, 2018).

Penelitian ini menunjukkan bahwa ada hubungan yang signifikan antara IMT dengan tekanan darah sistolik dan diastolik $(\mathrm{p} \leq .05)$ pada tabel 3 , dengan keeratan hubungan yang cukup dengan arah korelasi positif. Hal ini memberi implikasi bahwa semakin tinggi IMT maka semakin tinggi juga tekanan darah sistolik maupun diastolik. Hal ini sejalan dengan penelitian sebelumnya yang menunjukkan bahwa terdapat hubungan bermakna antara IMT dengan hipertensi (Febriyani and Sundari, 2016). Demikian juga penelitian yang dilakukan pada beberapa negara di Asia Selatan menyimpulkan bahwa bahkan batas bawah overweight-obesitas memiliki pengaruh pada peningkatan tekanan darah (Hossain et al., 2019).

Pada penelitian lain didapati bahwa kejadian hipertensi semakin tinggi pada kelompok obesitas dibandingkan dengan IMT yang normal. Selain itu, semakin tinggi kategori obesitasnya (obesitas I-III) semakin banyak yang ditemukan menderita hipertensi (Landi et al., 2018). Terjadinya tekanan darah tinggi akibat obesitas merupakan mekanisme yang beragam temasuk inflamasi kerja hormon dan saraf otonom yang saling berhubungan. Mekanisme tersbut menyebabkan gangguan fungsi pembuluh darah oleh karena disfungsi endotel yang akhirnya menyebabkan peningkatan tekanan darah (Cohen, 2018).

Uji hubungan antara aktifitas fisik dan tekanan darah (tabel 3) pada penelitian ini menunjukkan bahwa tidak ada hubungan signifikan ( $\mathrm{p} \geq .05)$. Hal ini dimungkinkan oleh karena sebagian besar responden $(63 \%)$ memiliki tingkat aktifitas normal dan $15 \%$ memiliki tingkat aktifitas tinggi. Aktifitas fisik berperan penting untuk mempertahankan tekanan darah normal. Resiko peningkatan tekanan darah berhubungan dengan kurangnya aktfitas fisik dan kelebihan berat badan ( $\mathrm{Li}$ et al., 2017). Individu yang memiliki aktifitas moderat sampai tinggi lebih jarang mengalami hipertensi, sehingga dianjurkan untuk dilakukan sebagi tindakan pencegahan terhadap hipertensi (You et al., 2018).

Penderita hipertensi yang melakukan latihan fisik sebagai intervensi mengalami penurunan tekanan darah yang siknifikan (Wen and Wang, 2017). Latihan fisik merupakan hal yang dianjurkan dan terbukti efisien dan efektif dalam penangan tekanan darah tinggi. Latihan fisik dapat mengurangi resiko kerusakan fungsi kognitif yang disebabkan oleh hipertensi (Rêgo et al., 2019). Bahkan latihan fisik yang dilakukan dalam satu waktu dan yang dilakukan rutin dalam waktu yang lama pada pasien hipertensi yang resisten terhadap obat antihipertensi menunjukan penurunan tekanan darah. Latihan fisik dapat mempengaruhi hemodinamika tubuh, fungsi saraf otonom dan resitensi pembuluh darah (Nascimento et al., 2017).

\section{KESIMPULAN}

Wanita dewasa di RW 13 Desa Cihanjuang Rahayu memiliki IMT yang tergolong obesitas dengan aktifitas normal dan tekanan darah yang mengalami peningkatan. Indeks Massa Tubuh memiliki hubungan yang signifikan dengan tekanan darah sistolik maupun diastolik. Dilain pihak tidak ada hubungan signifikan antara aktifitas fisik dengan tekanan darah. Wanita dewasa perlu melakukan usaha untuk menurunkan berat badan dalam upaya mengontrol tekanan darah. Penelitian dimasa yang akan datang diharapkan dapat menggali lebih jauh faktor lain seperti pola makan yang berhubungan dengan tekanan darah pada wanita. 


\section{DAFTAR PUSTAKA}

Abdul, M. et al. (2018) 'Trends, prevalence and risk factors of overweight and obesity among women of reproductive age in Bangladesh: a pooled analysis of five national cross- sectional surveys', pp. 1-12. doi: 10.1136/bmjopen-2017018468 .

Cohen, J. B. (2018) 'HYPERTENSION IN OBESITY AND THE IMPACT OF WEIGHT', Curr Cardiol Rep, 19(10). doi: 10.1007/s11886017-0912-4.HYPERTENSION.

Egan, B. M. (2017) 'Physical Activity and Hypertension', Hypertension, 69, pp. 404-406. doi:

10.1161/HYPERTENSIONAHA.116.08508.

Febriyani and Sundari, L. P. R. (2016) 'Hubungan indeks massa tubuh dengan kejadian hipertensi pada perempuan', Medika, 5(12), pp. $1-5$.

Hall, J. E. et al. (2015) 'Obesity-Induced Hypertension Interaction of Neurohumoral and Renal Mechanisms John', Circulation Research, 116(March), pp. 991-1006. doi: 10.1161/CIRCRESAHA.116.305697.

Hossain, F. B. et al. (2019) 'Association between body mass index ( BMI ) and hypertension in south Asian population: evidence from nationally- representative surveys', Clinical Hypertension. Clinical Hypertension, 25, pp. 19. Available at: https://doi.org/10.1186/s40885019-0134-8.

Jiang, S. et al. (2016) 'Obesity and hypertension ( Review )', Experimental and Therapeutic Medicine, 12, pp. 2395-2399. doi: 10.3892/etm.2016.3667.

Kim, B. et al. (2017) 'Obesity and Physical Activity', pp. 15-22.

Landi, F. et al. (2018) 'Body Mass Index is Strongly Associated with Hypertension : Results from the Longevity Check-Up', nutrients, 10(Cvd), pp. 1-12. doi: 10.3390/nu10121976.

Li, W. et al. (2017) 'The effect of body mass index and physical activity on hypertension among Chinese middle-aged and older population', Scientific Reports. Springer US, 7(1), pp. 1-7. doi: 10.1038/s41598-017-11037-y.
Lim, J. U. et al. (2017) 'Comparison of World Health Organization and Asia-Pacific body mass index classifications in COPD patients', International Journal of COPD, pp. 2465-2475.

Malinti, E. and Elon, Y. (2019) 'Hubungan asupan natrium, kalium, indeks massa tubuh, lingkar pinggang dengan tekanan darah pria dewasa muda', Riset Informasi Kesehatan, 8(1), pp. 1-8. doi: 10.30644/rik.v8i1.213.

Malinti, E. and Lola, F. (2018) 'Body Weight and Blood Pressure of Young Adult Women in Universitas Advent Indonesia', in Abstract Proceeding 6th International Scholar Conference, p. $110 . \quad$ doi: doi.org/10.35974/isc.v6i1.1415.

Nascimento, L. S. et al. (2017) 'Acute and chronic effects of aerobic exercise on blood pressure in resistant hypertension : study protocol for a randomized controlled trial', Trials. Trials, 18, pp. 1-8. doi: 10.1186/s13063-017-1985-5.

Nuttall, F. Q. (2015) 'Body Mass Index', Nutrition Today, 50(3), pp. 117-128. doi: 10.1097/NT.0000000000000092.

Pescatello, L. S. et al. (2019) 'Physical Activity to Prevent and Treat', Med. Sci. Sports Exerc., 51(6), pp. 1314-1323. doi: 10.1249/MSS.0000000000001943.

Rêgo, M. L. M. et al. (2019) 'Physical Exercise for Individuals with Hypertension : It Is Time to Emphasize its Benefits on the Brain and Cognition', Clinical medicine Insights: cardiology, 13, pp. 1-10. doi: 10.1177/1179546819839411.

Riskesdas (2018) Hasil Utama Riskesdas 2018. Available at: http://www.kesmas.kemkes.go.id/assets/upload/ dir 519d41d8cd98f00/files/Hasil-riskesdas2018 1274.pdf.

Stenholm, S. et al. (2017) 'Body mass index as a predictor of healthy and disease-free life expectancy between ages 50 and 75: a multicohort study', (February), pp. 769-775. doi: 10.1038/ijo.2017.29.

Wen, H. and Wang, L. (2017) 'Reducing effect of aerobic exercise on blood pressure of essential hypertensive patients', Medicine, 96, pp. 1-6. 
West, S. L. et al. (2018) 'The Epidemic of Obesity and Poor Physical Activity Participation : Will We Ever See a Change?', Journal of Functional Morphology And Kinesiology, 3(34). doi: 10.3390/jfmk3020034.

Whelton, P. K. et al. (2018) 'Clinical Practice Guideline: Executive Summary 2017 ACC / $\mathrm{AHA} / \mathrm{AAPA} / \mathrm{ABC} / \mathrm{ACPM} / \mathrm{AGS} / \mathrm{APhA} /$ ASH / ASPC / NMA / PCNA Guideline for the Prevention , Detection , Evaluation , and Management of High Blood Pressure in Adults : Executive Summary', Hypertension, 71, pp. 1269-1324.

doi:

10.1161/HYP.0000000000000066.

WHO (2018) 'Physical activity for health More active people for a healthier world : draft global action plan', Seventy-first world health assembly, (March), pp. 1-8.

You, Y. et al. (2018) 'Hypertension and physical activity in middle-aged and older adults in China', Scientific Reports, 8(1), pp. 1-8. doi: 10.1038/s41598-018-34617-y.

Youngwanichsetha, S. (2018) 'Journal of Nutrition \& Food Sciences Overweight, Obesity and Women Health', Journal of Nutrition \& Food Sciences, 8(4), p. 9600. doi: 10.4172/2155$9600.1000 \mathrm{e} 146$. 